\title{
Upregulation of metastasis-associated PRL-3 initiates chordoma in zebrafish
}

\author{
LI LI $^{12^{*}}$, HONGSHUN SHI $^{2 *}$, MINGMING ZHANG ${ }^{2}$, XIAOLING GUO $^{1}$, FANG TONG $^{2}$, \\ WENLIANG ZHANG ${ }^{2}$, JUNYI ZHOU ${ }^{2}$, HAIHE WANG ${ }^{2,3}$ and SHULAN YANG ${ }^{1}$ \\ ${ }^{1}$ Translational Medicine Centre, The First Affiliated Hospital, Sun Yat-sen University; \\ ${ }^{2}$ Department of Biochemistry, Zhongshan School of Medicine; ${ }^{3}$ Center for Stem Cell Biology \\ and Tissue Engineering, Sun Yat-sen University, Guangzhou, Guangdong CPZN 510080, P.R. China
}

Received November 12, 2015; Accepted January 15, 2016

DOI: $10.3892 /$ ijo.2016.3363

\begin{abstract}
The metastasis-associated phosphatase of regenerating liver-3 (PRL-3) plays multiple roles in progression of various human cancers; however, significance of its role during development has not been addressed. Here we cloned and characterized the expression pattern of zebrafish $\mathrm{prl}-3$ transcript and showed that it is ubiquitiously expressed in the first $24 \mathrm{~h}$ of development with both maternal and zygotic expressions. The transcripts become progressively restricted to the notochord, vessels and the intestine by $96 \mathrm{~h}$ post-fertilization. Notably, overexpression of zebrafish Prl-3 (zPrl-3) and human PRL-3 induces notochord malformation in zebrafish. This phenotype resembles chordoma and is confirmed by associated misexpression of notochord-specific markers. Clinical significance of the PRL-3 in chordoma is strongly suggested by detection of PRL-3 antigen in clinical chordoma specimens. Collectively, our results uncovered that aberrant overexpression of PRL-3 could initiate chordoma in early development and suggest the use of PRL-3 could be used as a predictor and a therapeutic target for chordoma.
\end{abstract}

\section{Introduction}

Protein-tyrosine phosphatase of regenerating liver-3 (PRL-3), also known as PTP4A3 (tyrosine phosphatase type IVA 3), is a protein with relatively small molecular weight of $22 \mathrm{kDa}$. It belongs to the protein tyrosine phosphatases superfamily (1), and contains three members, the PRL-1, PRL-2, and PRL-3. Of them, PRL-3 is known to be highly expressed in distant

Correspondence to: Dr Shulan Yang, Translational Medicine Centre, The First Affiliated Hospital of Sun Yat-sen University, 58 Second Zhonshan Road, Guangzhou, Guangdong CPZN 510080, P.R. China E-mail: yangshl3@mail.sysu.edu.cn

Dr Haihe Wang, Department of Biochemistry, Zhongshan School of Medicine, Sun Yat-sen University, 74 Second Zhonshan Road, Guangzhou, Guangdong CPZN 510080, P.R. China

E-mail: wanghaih@mail.sysu.edu.cn

Key words: PRL-3, chordoma, zebrafish, tumorigenesis metastatic sites of colon cancers (2). High level of PRL-3 expression was observed in other types of cancers, including breast (3), ovary $(4,5)$, liver (6), and stomach (7) tumors. Moreover, elevated PRL-3 expression correlates with cancer cell proliferation, motility, invasiveness, and tumor angiogenesis (8-10) in cancer cell line-based systems. Growing evidence has indicated that high expression level of PRL-3 is an adverse prognostic factor (11). Mechanistically, PRL-3 modulates multiple signaling pathways including Rho GTPase (12), Src (13), and PI3K AKT (14) in different tumors. All these observations indicate that PRL-3 plays an important role in various cancer in progression and metastasis.

Although evidence links PRL-3 expression to tumorigenesis and metastasis in tumor cells and tissues, expression pattern of PRL-3 during development and consequence of its general expression during embryogenesis is not known. PRL-3 expression in adult tissues is detected PRL-3 in the heart and skeletal muscle while moderate expression is detected in the pancreas $(15,16)$. Mouse PRL-3 is also detected in the villus epithelial cells of the small intestine (17). Importantly, PRL-3 protein has been detected in rat fetal heart and developing blood vessels, but not in adult rat or human heart and mature blood vessels (9). These observations suggest that PRL-3 expression pattern is developmentally regulated in mammals and PRL-3 may have potential functions in cell proliferation.

To our knowledge, the expression pattern of $\mathrm{prl}-3$ during vertebrate development and consequence of its aberrant upregulation has not been explored. In this study, we used zebrafish as our vertebrate model and determined the expression pattern of $\mathrm{prl}-3$ during different stages of zebrafish development by whole mount in situ hybridization. Interestingly, overexpression of either zebrafish Prl-3 (zPrl-3) or human PRL-3 (hPRL-3) led to notochord malformation reminiscent of chordoma which we confirmed with chordomaspecific markers. Relevance of the role of PRL-3 in chordoma is supported by immunochemical detection of human PRL-3 in clinical chordoma specimens.

\section{Materials and methods}

Fish lines and maintenance. Zebrafish (strain $\mathrm{AB}$ ) embryos were collected from the zebrafish model animal facility, 
institute of clinical and translation research, Sun Yat-sen University. The fish was maintained in a circulating rack system with alternate exposure of $14 \mathrm{~h}$ light and $10 \mathrm{~h}$ dark at $28.5^{\circ} \mathrm{C}$, and fed three times daily. Embryos were staged on hours of post fertilization (hpf) or days post fertilization (dpf) at $28.5^{\circ} \mathrm{C}$.

Whole mount in situ hybridization and imaging. The zebrafish prl-3 (zprl-3, ptp4a2a protein tyrosine phosphatase type IVA, member 2a, Gene ID: 449541) probe was designed to include the-3'-UTR region based on database (NM.001005583). Total mRNA isolated from zebrafish embryos was used for reverse transcription of the first-strand cDNAs. Zebrafish prl-3 (zprl-3) was amplified by PCR with a pair of primers (zPRL3-931F and zPRL3-1659R, Table I), cloned into the PGEM -T Easy Vector (Promega) and confirmed by sequencing. RNA probes of zprl-3 were labeled with digoxigenin-dUTP (DIG, Roche, cat no. 11277073910) by in vitro transcription and purified according to the manufacturer's instructions. Shh (sonic hedgehog) probe was used as described previously (18). Plasmid encoding $n t l$ (no tail) was a gift from Professor Vladimir Korzh, Institute of Molecular and Cell Biology, Singapore. Zebrafish embryos were fixed with $4 \%$ paraformaldehyde (PFA) in phosphate-buffered saline (PBS) overnight, followed by washing with PBST (0.1\% Tween in PBS). Embryos were then empirically treated by protease $\mathrm{K}$ (Roche, cat no. 3115844001) for appropriate time, depending on stage of embryo development. Embryos were post-fixed after digestion and washed in PBST before pre-hybridization in HYB buffer $(50 \%$ formamide, $5 \mathrm{X}$ standard saline citrate, $0.1 \%$ Tween-20, $50 \mu \mathrm{g} / \mathrm{ml}$ heparin, $0.5 \mathrm{mg} / \mathrm{ml}$ total yeast RNA, $9.2 \mathrm{mM}$ citric acid) at $65^{\circ} \mathrm{C}$ for $2 \mathrm{~h}$. Incubation with respective digoxigenin-dUTP labeled probes $(2 \mu \mathrm{g} / \mathrm{ml})$ was carried out at $65^{\circ} \mathrm{C}$ overnight. After removal of probes, embryos were washed at $65^{\circ} \mathrm{C}$ with $100,75,50$ and $25 \%$ formamide in $2 \mathrm{X}$ SSCT (15 mM citrate, $150 \mathrm{mM} \mathrm{NaCl}, 0.1 \%$ Tween-20, $\mathrm{pH}$ 7.0). This was followed by a 0.2X SSCT wash. Embryos were then incubated in MABT buffer $(150 \mathrm{mM}$ maleic acid, $100 \mathrm{mM} \mathrm{NaCl}, 0.1 \%$ Tween-20, pH 7.5) and blocked for $2 \mathrm{~h}$ with blocking reagent (Roche) dissolved in MABT. Alkaline phosphatase (AP)-conjugated anti-DIG antibody (Roche, cat no. 11093274910) diluted at 1:2,000 was added and incubated overnight at $4^{\circ} \mathrm{C}$. This was followed by 4 times PBST washes, and 1 wash with $\mathrm{pH}$ adjusted Tris- $\mathrm{HCl}$ staining buffer (0.1 M NaCl, $5 \mathrm{mM} \mathrm{MgCl}$, $0.1 \mathrm{M}$ Tris-HCl, $0.1 \%$ Tween-20, $\mathrm{pH}$ 9.2). Proper staining was initiated with the addition of NBT and BCIP to the staining buffer $(54 \mu \mathrm{l}$ of $50 \mathrm{mg} / \mathrm{ml} \mathrm{NBT}$ and $42 \mu \mathrm{l}$ of $75 \mathrm{mg} / \mathrm{ml}$ BCIP in $10 \mathrm{ml}$ Tris- $\mathrm{HCl}$ staining buffer) until the embryo was stained with visually acceptable signal to noise ratio. Stained embryos were imaged using a Leica DFC550 camera attached to a stereoscope (LeicaM205FA). Image contrasts were processed by Photoshop CS.

Northern blot hybridization. Total RNA was extracted from zebrafish embryos at their indicated stages, using TRIzol (Life Technologies, cat no. 15596026). Ten $\mu \mathrm{g}$ RNA was ran by formaldehyde-based denaturing gel and transferred onto nylon membrane (GE, cat. no. RPN303B) and fixed with UV crosslinker. Northern blot hybridization was carried out following the manufacturer's instructions (Roche, cat no. 12039672910) using the same digoxigenin-labeled zprl-3 antisense probes as used in zebrafish whole mount hybridization.

5'RACE of zebrafish PRL-3 and microinjection of PRL-3 mRNA and its plasmids into zebrafish embryos. Total RNA was extracted from $2 \mathrm{dpf}$ embryos. 5'-RACE of zprl-3 was performed with Ambion's FirstChoice ${ }^{\circledR}$ RLM RACE kit with indicated primers (Table I) according to the manufacturer's instructions. Encoding regions of both zebrafish and human PRL-3 with their proximal part of 5'UTR fragments were amplified by PCR using iProof High-Fidelity PCR kit (Bio-Rad, cat no. 172-5331) and cloned into pCS2 plasmids for functional mRNA synthesis. Negative controls used in the overexpression experiments contain nonsense mutantions of zebrafish prl-3 (zprl-3) and human PRL-3 (hPRL-3) are obtained using QuickChange Site-Directed Mutagenesis kit (Stratagene, cat no. 200518). PCS2-zprl-3 and PCS2-hPRL-3 were used as templates to produce the initiation codon point mutation (ATG $\rightarrow$ TAG) of PRL-3 following the manufacturer's instructions. The indicated primers for mutations are also listed in Table I. All above mentioned constructs were validated by DNA sequencing. Functional zprl-3 and $h P R L-3$ mRNAs and their nonsense mRNAs were synthesized using the Message Machine kit (Ambion, cat no. AM1340). mRNAs (75-100 pg) and injected into zebrafish embryos at one-cell stage with Microinjector (Warner PLI-100A). hPRL-3 overexpression was achieved by simultaneous co-injection of $100 \mathrm{pg}$ plasmids encoding PEGFP-PRL-3 (19) and PEGFP into one-cell stage zebrafish embryos. Embryos injected with nonsense mRNA were treated as normal controls.

Western blot analyses. Zebrafish embryos were collected, washed with pre-cooled PBS and pipetted up and down to remove yolks. Fifteen embryos were disintegrated in lysis buffer containing protease inhibitors for $1 \mathrm{~h}$ on ice. Afterward, the lysates were centrifuged at $4^{\circ} \mathrm{C}$ and the supernatants were collected. Equal amounts of proteins were separated by SDS-PAGE and transferred onto a polyvinylidene fluoride membrane (PVDF, Roche, cat. no. 03010040001). The transferred membranes were blocked in 5\% skim milk for $1 \mathrm{~h}$ and then incubated with primary antibodies at $4^{\circ} \mathrm{C}$ overnight. After that, membrane was incubated with secondary antibodies at room temperature for $1 \mathrm{~h}$. Signals were detected using the enhanced chemiluminescence system (ELC, Millipore, cat no. WBKLS0500) according to the manufacturer's instructions. Because zebrafish PRL-3 has a high identity to human PRL-3, the human PRL-3 monoclonal antibody (clones 318) was used to detect the overexpression of zebrafish PRL-3 in this analysis as described previously (4).

$H \& E$ staining. Embryos were PFA-fixed, paraffin-embedded and sliced into 5- $\mu \mathrm{m}$ thickness with Leica Microtome (RM2135). This is followed by dewaxing in fresh xylene twice for $15 \mathrm{~min}$ each. All slides were then subjected to stepwise rehydration with 100, 95, 80 and $75 \%$ ethanol and water followed by hematoxylin staining for $2 \mathrm{~min}$. Stained slides were subsequently rinsed in distilled water and immersed briefly in $1 \%$ acid alcohol $(1 \% \mathrm{HCl}$ in $70 \%$ ethanol). Treated slides were immediately stained with eosin solution for 10-30 sec, followed by stepwise dehydration in $75,80,95$ 
Table I. Primers used in this study.

\begin{tabular}{lll}
\hline Name & \multicolumn{1}{c}{ Sequence $\left(5^{\prime} \rightarrow 3^{\prime}\right)$} & Application \\
\hline zPRL-3-931F & 5'-GAAATATCGGCCCAAACAGAGACT-3' & For probe \\
zPRL-3-1659R & 5'-CAGATAAACACGCAGAAGAAACAT-3' & For probe \\
zPRL-3-inner (500R) & 5'-GTCGGTTCATGCGAGCCATA-3' & For 5'RACE \\
zPRL-3-outer (568R) & 5'-GGTGGAGTTTGTTGGGTTGT-3' & For 5'RACE \\
zPRL-3-470F-Cla1 & 5'-CCATCGATGGAAGCACAACTATGGCTCG-3' & For mRNA \\
zPRL-3-1010R-Xho1 & 5'-CCGCTCGAGTTCGCAGTCACATGATACAGCAC-3' & For mRNA \\
zPRL-3-mutation-F & 5'-GAAGCACAACTTAGGCTCGCTAGAACCGACCGG-3' & For nonsense mRNA \\
zPRL-3-mutation-R & 5'-CCGGTCGGTTCTAGCGAGCCTAAGTTGTGCTTC-3' & For nonsense mRNA \\
hPRL-3-845F-Cla1 & 5'-CCATCGATGCCACCAATGGCTCGGATGAACCG-3' & For mRNA \\
hPRL-3-1378R-Xho1 & 5'-CCGCTCGAGGAGCTACATAACGCAGCACCG-3' & For mRNA \\
hPRL-3-mutation-F & 5'-CATCGATGCCACCATAGGCTCGGTAGAACCGC-3' & For nonsense mRNA \\
hPRL-3-mutation-R & 5'-GGTTCTACCGAGCCTATGGTGGCATCGATGGG-3' & For nonsense mRNA
\end{tabular}

The nonsense mutation position is marked in bold.

and $100 \%$ ethanol. Slides were then cleared with xylenne and mounted in neutral balsam before microscopic imaging (Zeiss Axio Imager Z1).

Immunohistochemistry (IHC). IHC experiments were conducted using monoclonal PRL-3 antibody (clone 318) (4) to examine PRL-3 expression in clinical chordoma specimens collected from the First Affiliated Hospital, Sun Yat-sen University. The clinical chordoma specimens were formalinfixed, paraffin-embedded and sliced into 5- $\mu \mathrm{m}$ thickness. Slides were baked at $60^{\circ} \mathrm{C}$ for $1 \mathrm{~h}$ and then dewaxed in xylene for $10 \mathrm{~min}$. This step was repeated twice. Treated slides were rehydrated with $100 \%, 95 \%, 80 \%, 75 \%$ ethanol and PBS, followed by antigen retrieval in $0.01 \mathrm{M}$ sodium citrate buffer at $95^{\circ} \mathrm{C}$ for $15 \mathrm{~min}$. Slides were then cooled and washed with PBS for 3 times, incubated with $3 \% \mathrm{H}_{2} \mathrm{O}_{2}$ for $10 \mathrm{~min}$, and then washed several times with PBS. Treated slides were blocked in $10 \%$ goat serum for $2 \mathrm{~h}$ and then incubated at $4^{\circ} \mathrm{C}$ overnight with PRL-3 antibodies diluted at 1:200. After rinsing with PBS, slides were incubated with secondary antibodies for $30 \mathrm{~min}$ at room temperature. Colorimetric detection was achieved with 3, 3-diaminobenzidine (DAB). The reaction was terminated with water and slides were mounted in neutral balsam, observed and imaged using Zeiss Axio Imager Z1 microscope.

\section{Results}

The expression pattern of PRL-3 in zebrafish. Evolutionally, the strength of sequence identity between orthologous genes parallels their conservation of gene functions. Database search identified zebrafish Prl-3 and found that it shares 90\% protein identity with its human orthologue (Fig. 1A), suggesting similar roles during vertebrate development. Therefore, understanding dynamic expression patterns of prl-3 in zebrafish may help to appreciate its physiological role in mammals. The expression pattern of prl-3 during zebrafish development was examined by whole mount in situ hybridization (ISH) using zPrl-3 antisense dig labeled probes. Zebrafish prl-3 transcripts were detected as early as the 8-cell stage of embryonic development (Fig. 1B), indicating prl-3 as a maternally expressed transcript. Ubiquitous prl-3 mRNA expression continues in the whole embryo from $12 \mathrm{hpf}$ (Fig. 1C) to $24 \mathrm{hpf}$ (Fig. 1D), suggesting generic importance of prl-3 in the first $24 \mathrm{~h}$ of embryogenesis. Tissue restricted expression was detected from $48 \mathrm{hpf}$ where zebrafish prl-3 was enriched in the zebrafish brain (br), suggesting a role in neurogenesis (Fig. 1E). Additional sites where $p r l-3$ transcripts are detected include the digestive tract (dt), muscles (mu) and vessels (ve) (Fig. 1E). Increasingly restricted expression continues from 72 to $96 \mathrm{hpf}$ where $\mathrm{prl}-3$ mRNA expression is now concentrated in specific organs, including the esophagus (es), notochord (no), vessels (ve), and intestine (in) (Fig. 1F and G), suggesting its potential role in their organogenesis. Continued detection of prl-3 transcripts in the digestive tracts from $48 \mathrm{hpf}$ (Fig. 1E) to $96 \mathrm{hpf}$ (Fig. 1F and $G$ ) suggest a significant role in the development of the digestive system. By 96 hpf prl-3 transcripts are restricted to the endothelia of zebrafish intestine and stomach (Fig. 1H-J). Trace expression of $\mathrm{prl}-3$ transcripts is also detected in the liver (li) at $96 \mathrm{hpf}$ (Fig. 1G). Our ISH results here clearly document the dynamic expression of prl-3 in developing tissues. These dynamic changes of prl-3 mRNA expression from 24 to $96 \mathrm{hpf}$ were additionally verified using northern hybridization. Relative expression value at tested developmental stages is numerically indicated under each band. Computed results showed reduction of $\mathrm{prl}-3$ transcripts with progressive embryonic development (Fig. 1K), in line with that observed in ISH.

Overexpression of Zebrafish PRL-3 induces notochord malformation. The dynamic expression pattern of prl-3 mRNA suggests a regulated role in embryonic development. Overt overexpression of prl-3 in zebrafish embryos will address the consequence of perturbing prl-3 dosage during development. To induce overt expression of endogenous prl-3 expression, we microinjected zebrafish $\mathrm{prl}-3$ mRNA into one cell stage embryos and observe the impact on embryonic development. 
A

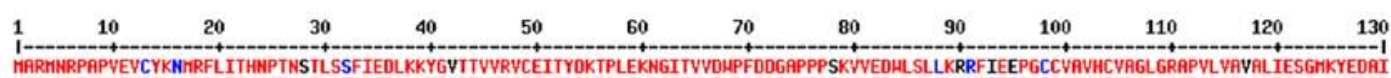

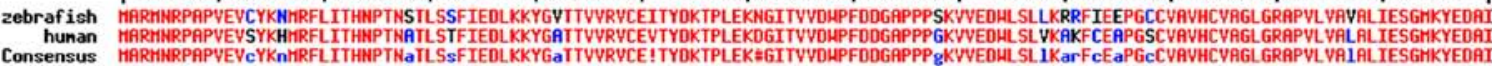

$131 \quad 140 \quad 150 \quad 160 \quad 170173$

zebrafish OFIRQKRRGAINSKQLTYLEKYRPKQRLRYKHPHIFKNKCCIH

hunan
Consensus
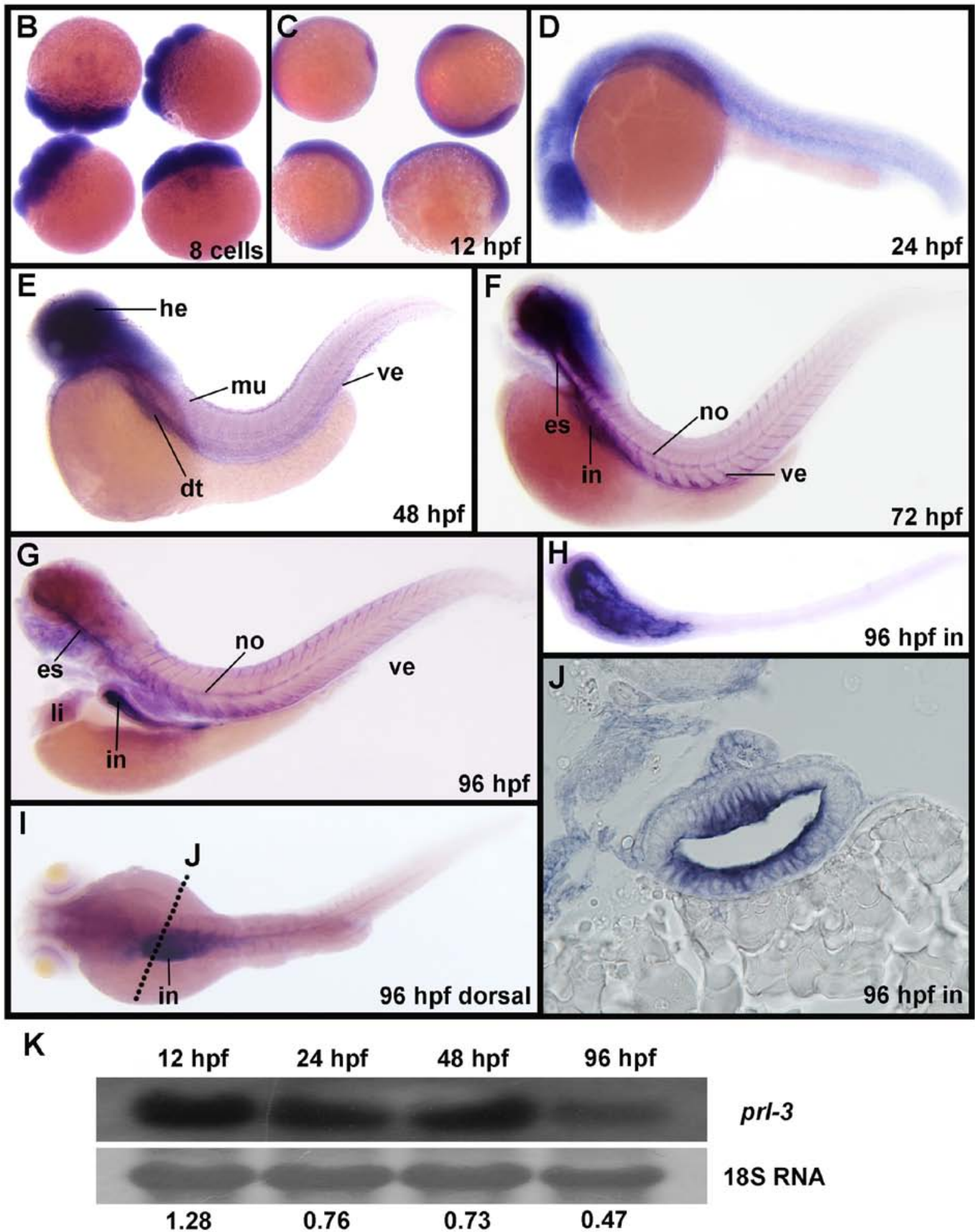

Figure 1. Dynamic expression pattern of prl-3 transcripts in zebrafish embryo development. (A) Amino acid sequence alignment of human and zebrafish PRL-3 protein. The identical amino acids are highlighted in red. (B-G) Prl-3 mRNA expression pattern in zebrafish by whole mount in situ hybridization of embryos with prl-3 specific antisense probes. Typical lateral views of embryos at 8-cell stage (B), 12 h post-fertilization (hpf) (C), 24 hpf (D), 48 hpf (E), 72 hpf (F), and in $96 \mathrm{hpf}(\mathrm{G})$ are presented. (H) Intestines peeled from embryos at $96 \mathrm{hpf}$ for in situ hybridization. (I) Dorsal view of Prl-3 expression in the intestines of the whole embryos. Dotted line indicates the transection of zebrafish larvea in $(\mathrm{J})$. ( $\mathrm{J})$ In situ hybridization of Prl-3 in the transectioned intestines of embryos in $96 \mathrm{hpf}$. (K) Northern blot analysis of prl-3 expression in WT embryos at 24, 48, 72 and 96 hpf. The ratio of prl-3 mRNA level versus $18 \mathrm{~S}$ RNA level is shown under each lane. Es, esophagus; dt, digestive tract; he, head; in, intestine; li, liver; no, notochord; ve vessel. 

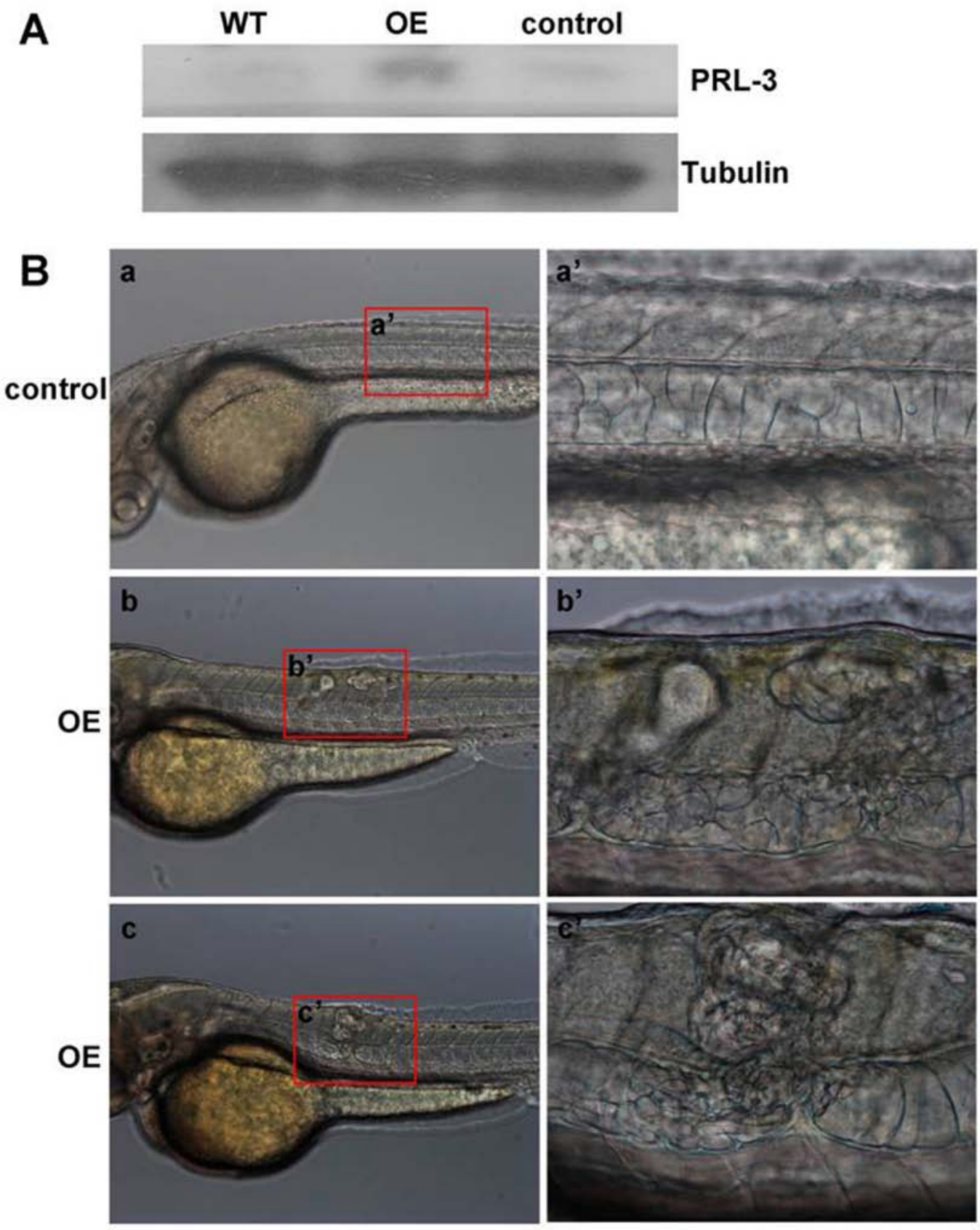

Figure 2. PRL-3 overexpression induces notochord malformation in zebrafish development. (A) Western blots of Prl-3 in normal zebrafish (WT), prl-3 overexpressing (OE) and nonsense mRNA-microinjected zebrafish (control). Tubulin is used as a loading control. (B) prl-3 overexpression induces notochord malformation in zebrafish. Representative images of lateral view of control embryos (a and a') and overexpression (OE) embryos (b, b', c and c') embryos are photographed at $48 \mathrm{hpf}$ under bright field. Each highlighted region in the left column is imaged under higher magnification and shown in the right panels accordingly.

Control population was microinjected with $\mathrm{prl}$-3 nonsense mRNA (by mutation of ATG $\rightarrow$ TAG) instead. Due to zebrafish PRL-3 having a high identity to human PRL-3, the human antibody was used to detect this protein. Western blot analyses supported successful translation of the microinjected prl-3 mRNA into PRL-3 protein as it contains the highest PRL-3 protein level when compared to wild-type or control population injected with the nonsense control mRNA (Fig. 2A). Developmental deformations were then tracked at 12, 24 , 30, 50 and 96 hpf. Notochord deformation characterized by aberrant cellular proliferation in and around the notochord.
Our results demonstrated that the notochord cells of control embryos are neatly aligned into a column (Figs. 2B-a and -a', and $3 \mathrm{~A}$ and $\mathrm{A}^{\prime}$ ), whereas consistent defects of bulked lumps were observed in the PRL-3 overexpression (OE) embryos (Figs. 2B-b, b', c and c', and 3B, B', C, C', D and D'). Statistical analysis confirmed that the incidence of notochord abnormality between embryos with PRL-3 overexpression and controls is statistically significant (Table II). Furthermore, H\&E staining of PRL-3 OE embryos at $2 \mathrm{dpf}$ confirmed aberrant cellular proliferation in the vicinity of the malformed notochord. The clear difference from normal control notochord cells (Fig. 4A 

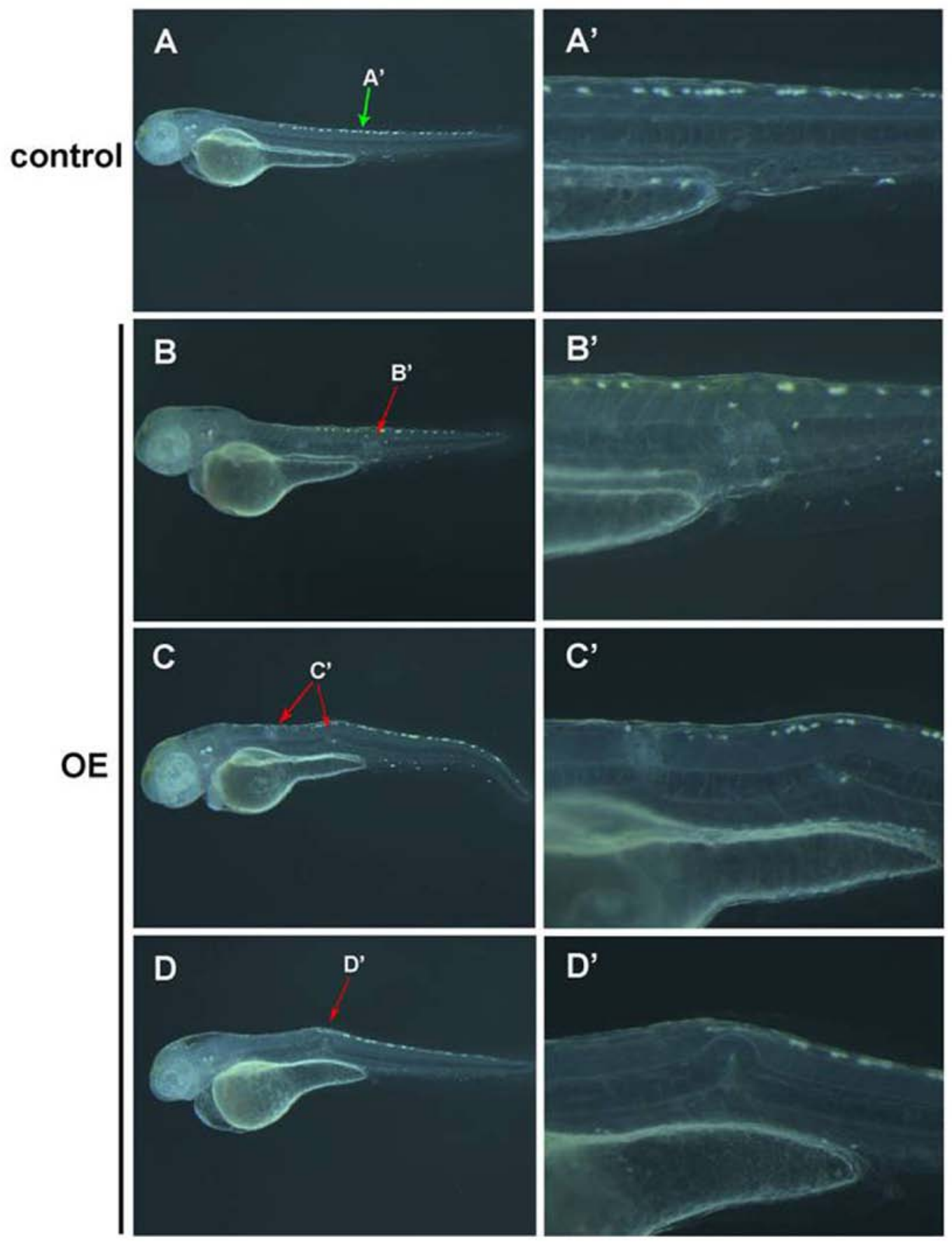

Figure 3. Notochord malformation caused by ectopic expression of prl-3. (A-C) Representative images of embryos at 48 hpf under dark field. Lateral views of control embryos (A and $\mathrm{A}^{\prime}$ ) and knockdown (KD) embryos (B, B', C, C', D and $\left.\mathrm{D}^{\prime}\right)$. Marked regions in the left columns are accordingly amplified and shown in the right panels.

Table II. Statistical data of notochordoma occurrence rate.

\begin{tabular}{lrrr}
\hline Groups & $\begin{array}{l}\text { Notochordoma } \\
\text { occurrence rate }\end{array}$ & P-value \\
\hline zPRL-3 mRNA & $38 \%$ & $(47 / 125)$ & $\mathrm{P}<0.0001$ \\
zPRL-3 nonsense mRNA & $5 \%$ & $(48 / 1021)$ & \\
hPRL-3 mRNA & $24 \%$ & $(63 / 267)$ & $\mathrm{P}<0.0001$ \\
hPRL-3 nonsense mRNA & $3 \%$ & $(21 / 630)$ & \\
\hline
\end{tabular}

Statistical analysis by $\chi^{2}$ test using SPSS. and B) are large vacuolated epithelial cells, regularly aligned along a primary axis in PRL-3 OE embryos (Fig. 4C-H black box). Taken together, our results indicated that the observed notochord malformation could be the typical phenotype of chordoma-like malignant tumor that arise from remnants of the embryonic notochord, with its origin in the bones of the axial skeleton (20).

The notochord abnormality induced by PRL-3 overexpression is chordoma. The zebrafish notochord is an embryonic midline structure that plays an structural role in vertebrate development (21) and shh is used as a molecular probe for 


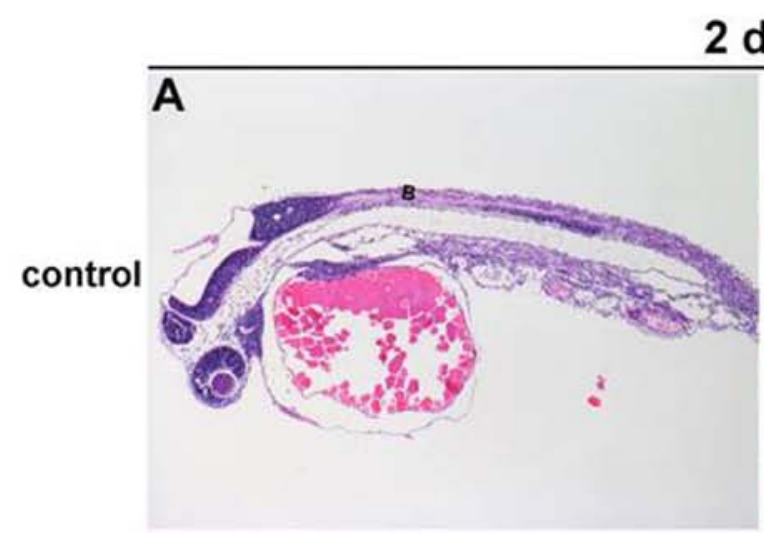

\section{$2 \mathrm{dpf}$}
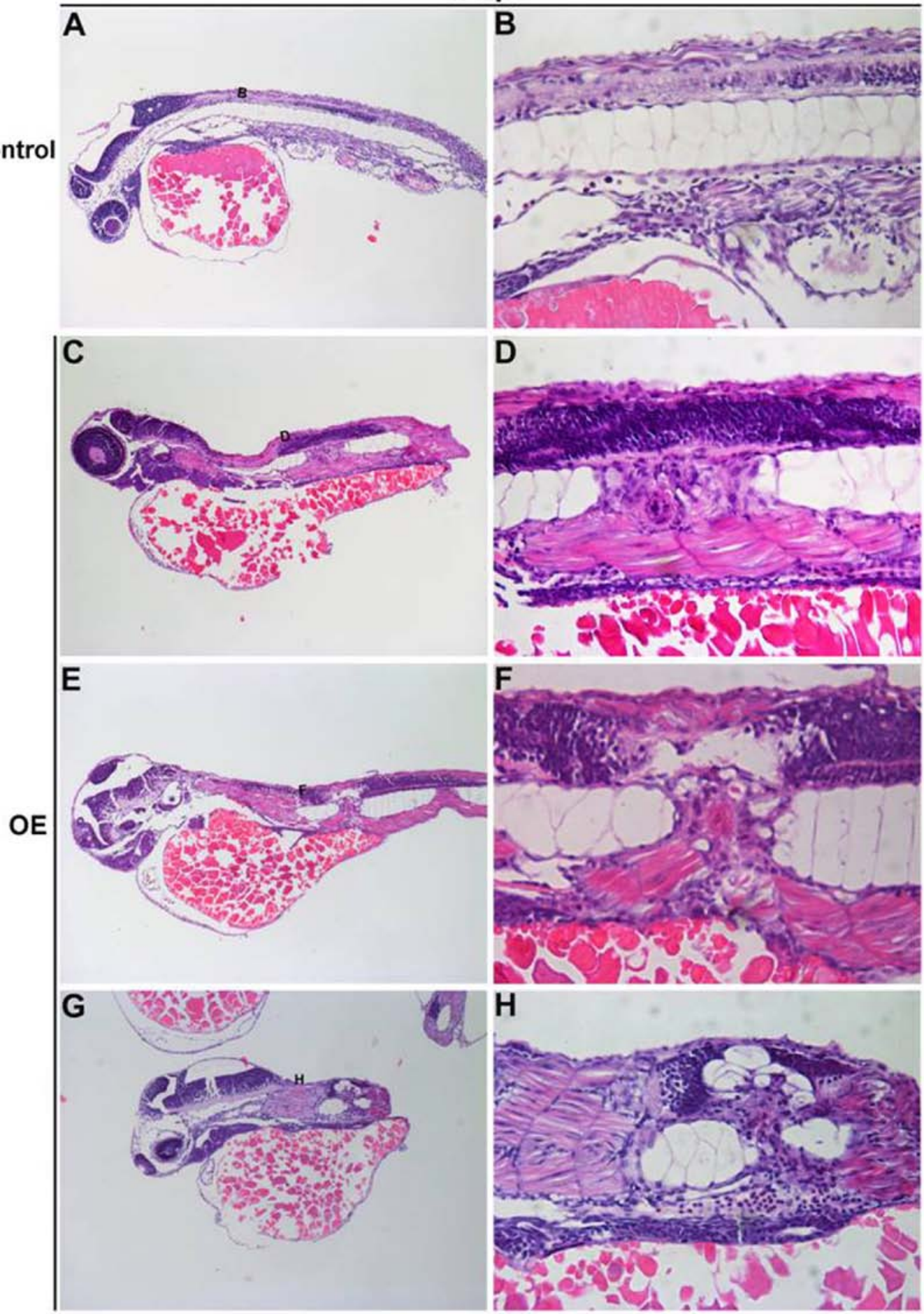

Figure 4. Pathological analyses of notochord malformation induced by PRL-3 overexpression. (A and B) H\&E staining of notochords in control embryos; (C-H) H\&E staining of the abnormal notochords in prl-3 overexpressing embryos at $2 \mathrm{dpf}$. (B, D, F and H) Highlighted portions of whole view embryos in left panels, taken under higher magnification and shown in the right panels accordingly.

notochord in early zebrafish embryo development (22-25). To clarify whether the observed notochord malformation is a result of notochord proliferation, ISH was performed with antisense shh probes. Our results showed that no ectopic $s h$ mRNA expression was detected in control population (Fig. 5A-a-c), however, the enrichment of $s h$ mRNA in domains of malformed notochord was observed, which was consistently observed at various developmental stages at 2, 3 and $4 \mathrm{dpf}$ (Fig. 5A-d-i). The above results suggest the observed aberrant cellular proliferation was attributed to the immature and undifferentiated notochord cells.

Given that chordoma is arisen from notochord remnants of the early embryos, it is recognized that accumulation of $s h h$ positive cells in notochord is the phenotype of chordoma. In 
A shh probe

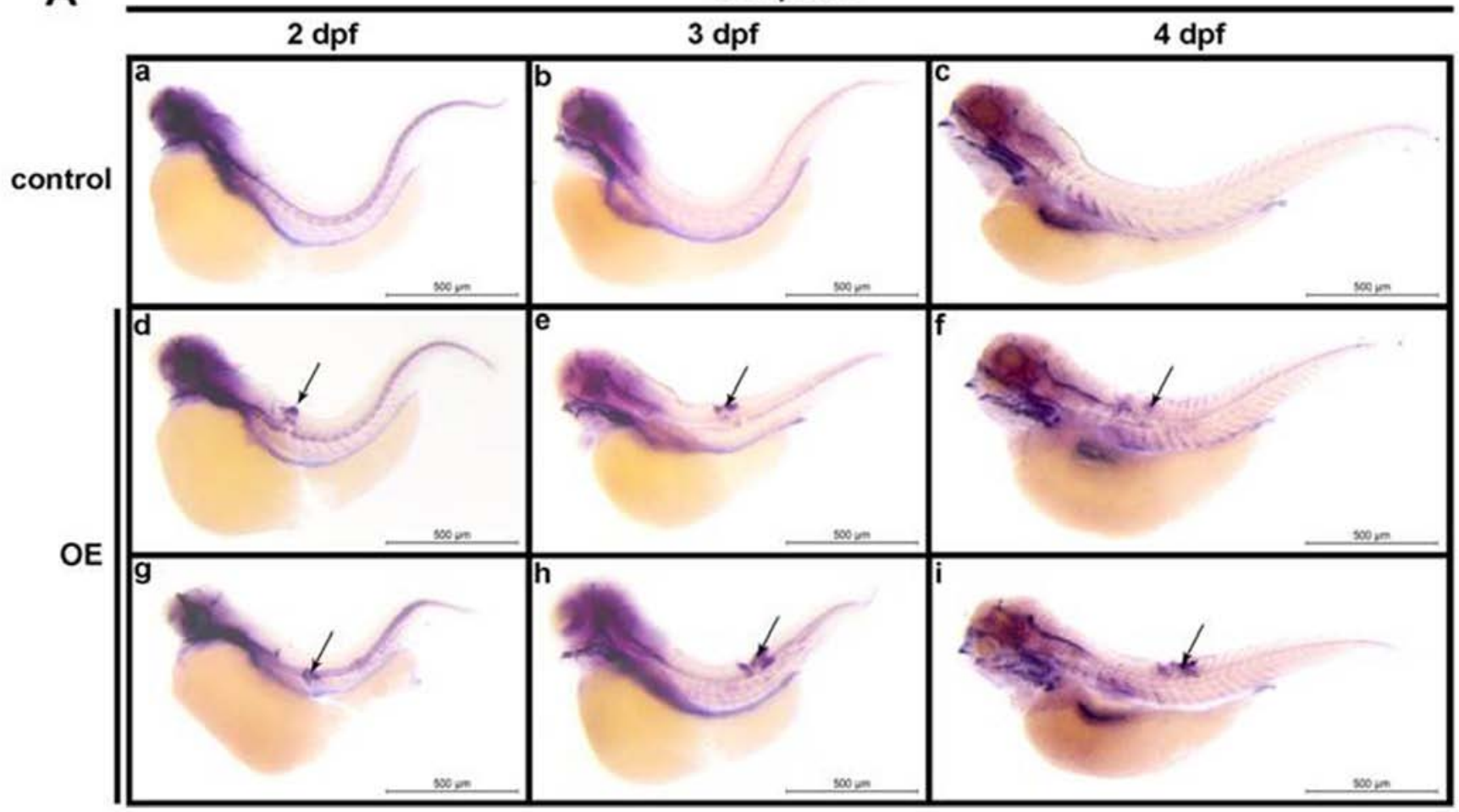

B ntl probe

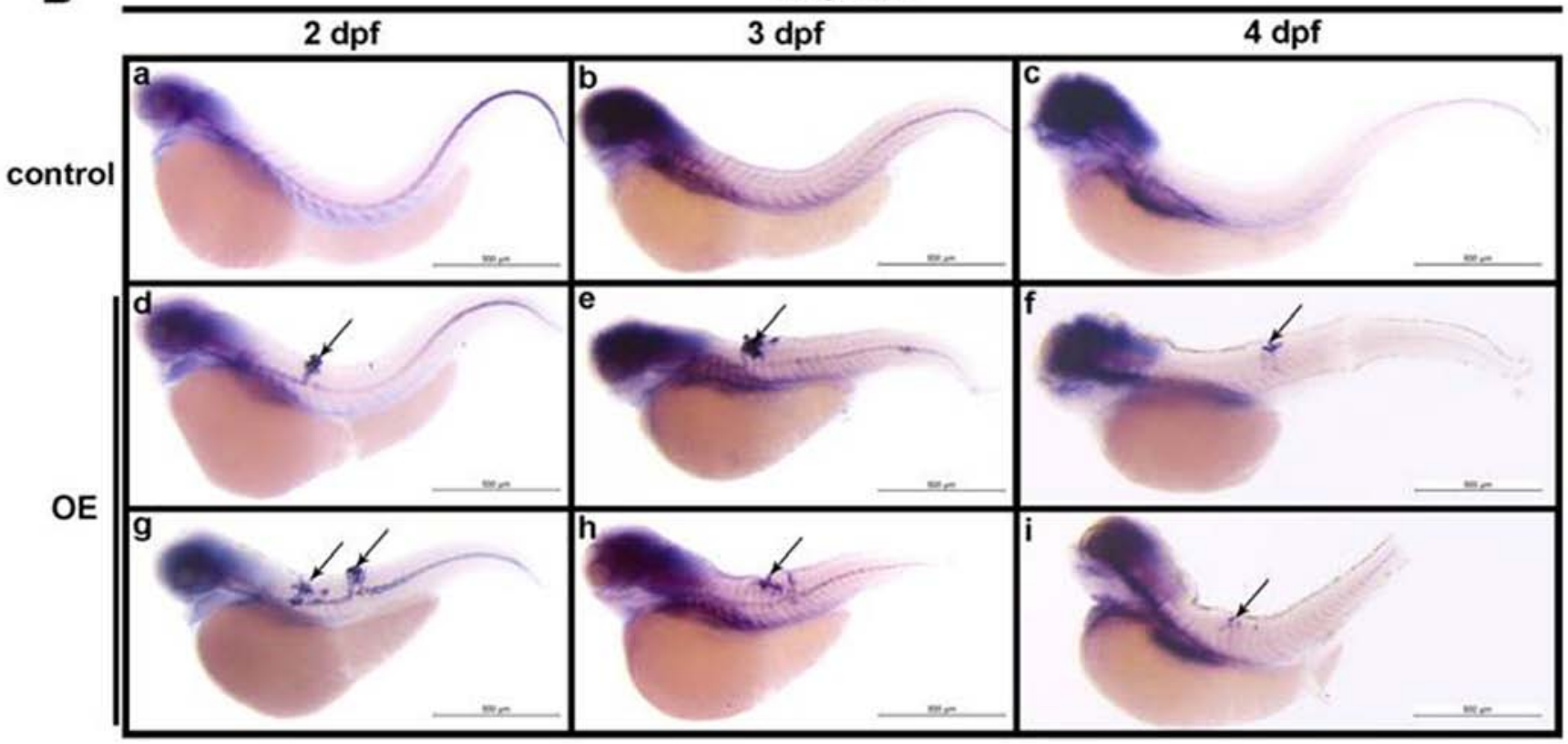

Figure 5. Identification of notochord malformation as chordoma by in situ hybridization of shh and $n t l$ expression. (A) Whole mount in situ hybridization of shh in control embyos at $2 \mathrm{dpf}(\mathrm{a}), 3 \mathrm{dpf}(\mathrm{b})$, and $4 \mathrm{dpf}$ (c), compared with that in notochord malformation induced by prl-3 upregulation (OE) at $2 \mathrm{dpf}$ (d and g), $3 \mathrm{dpf}(\mathrm{e}$ and $\mathrm{h}$ ), and $4 \mathrm{dpf}$ (f and i). The notochord malformation areas with shh positive signals are indicated with arrows. (B) Whole mount in situ hybridization of chordoma-specific $n t l$ in normal control embyos at $2 \mathrm{dpf}$ (a), $3 \mathrm{dpf}$ (b), and $4 \mathrm{dpf}$ (c), compared with that in notochord malformation induced by prl-3 upregulation (OE) at $2 \mathrm{dpf}(\mathrm{d}$ and g), $3 \mathrm{dpf}$ (e and h), and $4 \mathrm{dpf}$ (f and i). The notochord malformation areas with $n t l$-positive signals are indicated with arrows. All bars are shown as $500 \mu \mathrm{m}$.

zebrafish, $N t l$ (no tail), as a hallmarked transcription factor, is typically expressed in the immature notochord (26-28), and continuous $\mathrm{Ntl}$ expression endorses the immature notochord expansion as neoplasia, which is coincident to the clinical diagnosis of chordoma with brachyury as a specific biomarker $(29,30)$. As zebrafish $n t l$ is orthologous gene to brachyury, which has been evaluated in mice $(26,31,32)$, we thus clarified whether the phenotype induced by $p r l-3$ mRNA overexpres- 


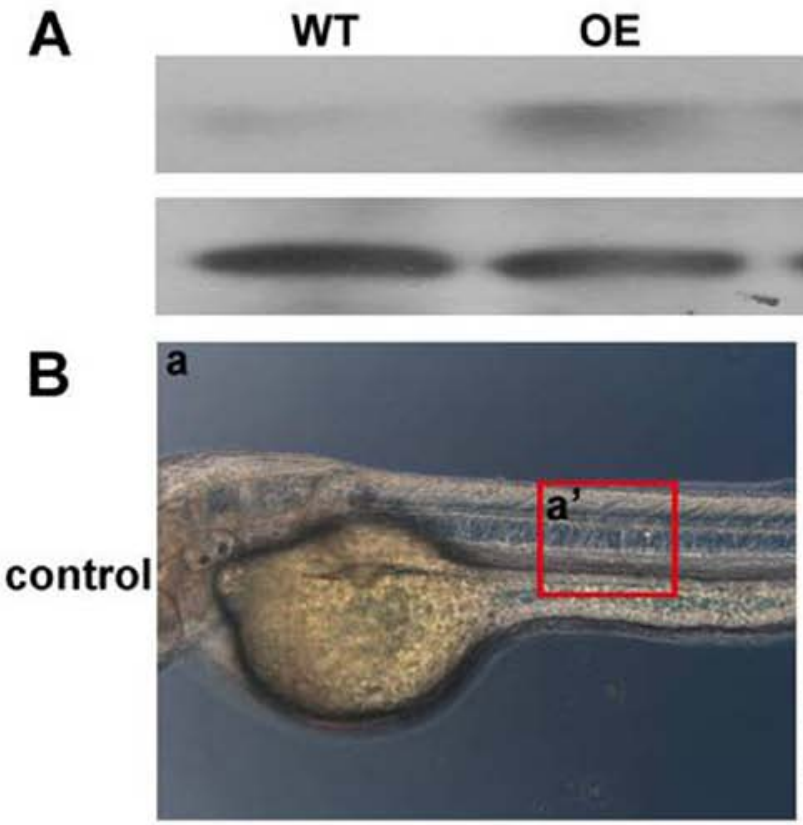

control

\section{PRL-3}
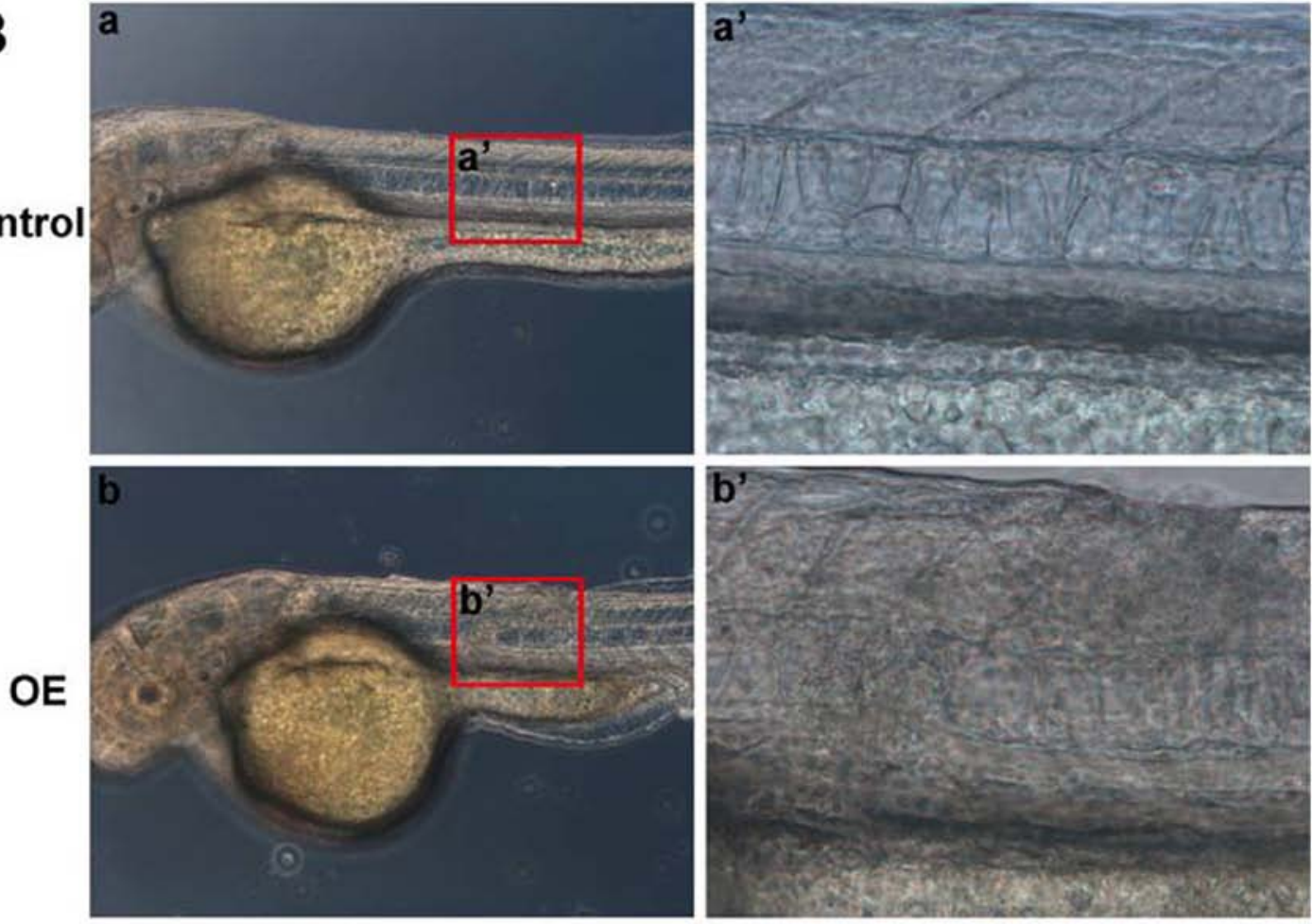

\section{Tubulin}
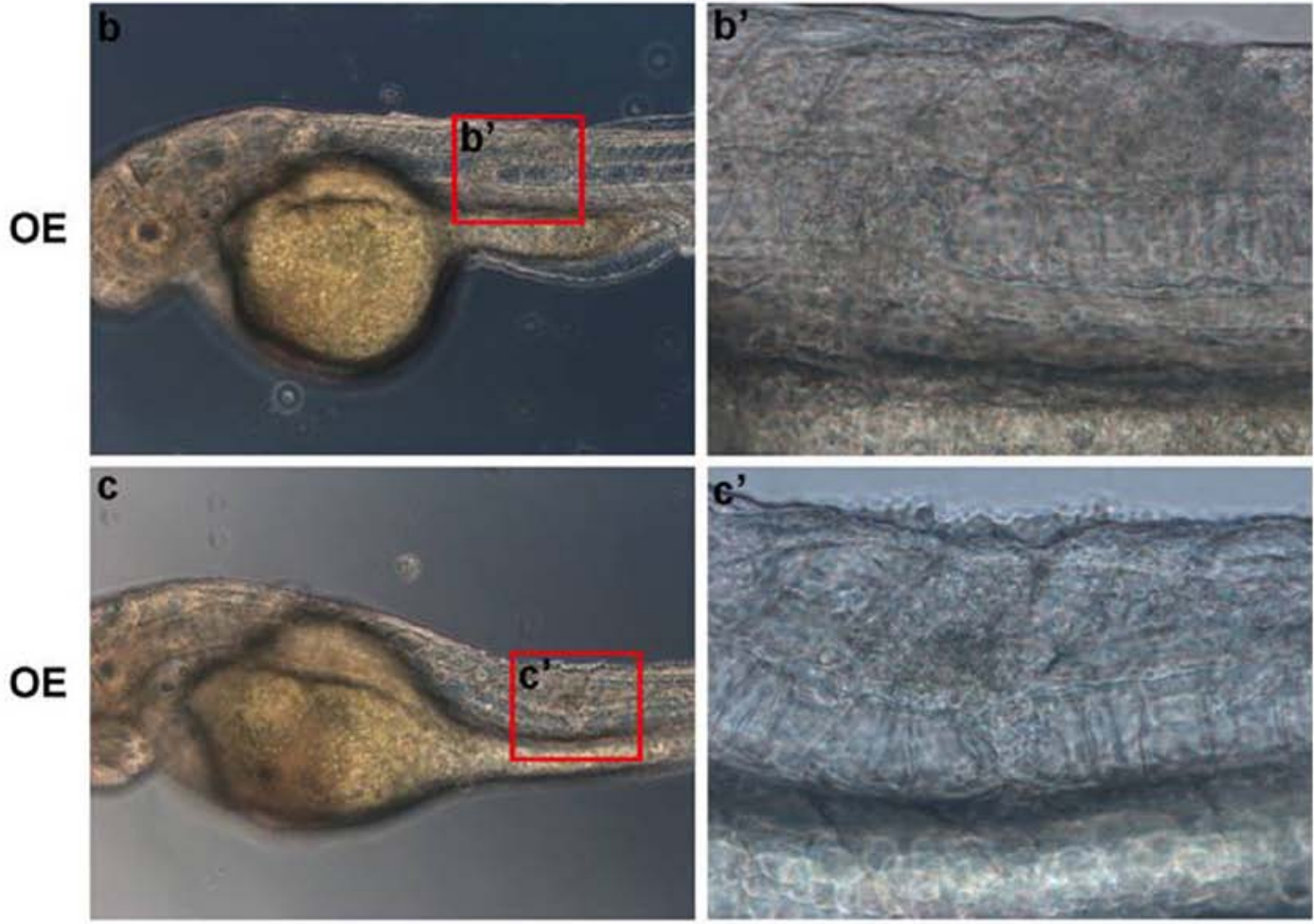

Figure 6. Human PRL-3 overexpression also induces notochord malformation in zebrafish. (A) Western blots of human PRL-3 in zebrafish (WT), PRL-3 overexpressing (OE) and nonsense mRNA-microinjected zebrafish (control). Tubulin is used as a loading control. (B) Human $P R L-3$ overexpression induces notochord malformation in zebrafish. Representative images of lateral view of control embryos (a and a') and human $P R L-3$ overexpression (OE) embryos (b, b', c and c') embryos were photographed at $48 \mathrm{hpf}$ under bright field. Each highlighted region in the left column is imaged under higher magnification and shown in the right panels accordingly.

sion is chordoma by ISH with zebrafish $n t l$ probe. Our results revealed that as notochord cells become vacuolated, the expression of $n t l$ is extinguished in the notochord of control embryos (Fig. 5B-a-c). In contrast, we observed the maintenance of $n t l$ expression in 3 dpf specimens with PRL-3 overexpression, and the ectopic masses of cells detected in notochord malformation regions are all $n t l$-positive till 4 dpi (Fig. 5B-d-i), supporting the chordoma phenotype. Using $s h h$ and $n t l$ probes, our results confirmed that notochord abnormalities induced by PRL-3 overexpression during embryo development is a result of chordoma.

Overexpression of orthologues human PRL-3 also leads to chordoma in zebrafish. We showed that zebrafish Prl-3 overexpression can initiate chordoma in early zebrafish development. To check whether overexpression of the human orthologue 


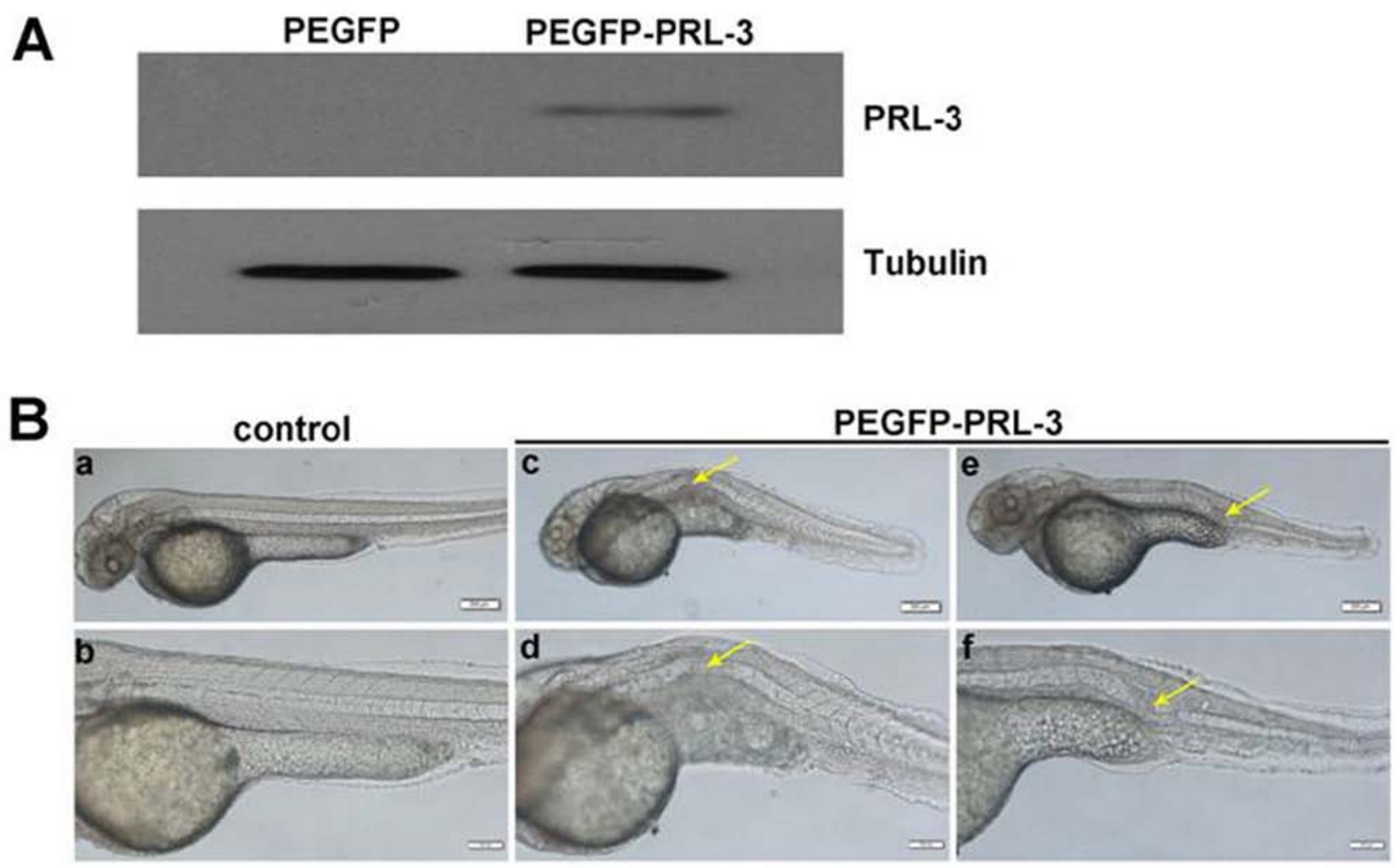

Figure 7. Notochord malformation caused by human GFP-PRL-3 overexpression. (A) Detection of human GFP-PRL-3 overexpression in zebrafish by western blots. Tubulin is used as a loading control. (B) Representative images of embryos at $48 \mathrm{hpf}$ under bright field. Lateral views of control embryos (a and b) and overexpression (OE) embryos (c-f). Marked regions in the indicated columns are amplified and shown in the lower panels accordingly. Arrows point to the areas with notochord malformation.

results in a similar outcome, human $P R L-3$ mRNA was microinjected into one-cell embryos. Endogenous PRL-3 level reflected in the control population was injected with human PRL-3 nonsense mRNA. Additionally, plasmids encoding eGFP-PRL-3 (EGFP-PRL-3) (19) and eGFP alone were also microinjected into zebrafish embryos at one-cell stage to upregulate hPRL-3 expression. Western blot results confirmed successful expression of the exogenous human PRL-3 RNA (Fig. 6A) and the GFP-PRL-3 (Fig. 7A) in injected zebrafish embryos while level of PRL-3 in control is comparable to un-injected wild-type. Embryos with notochord malformation were observed by $30 \mathrm{~h}$ post-injection and appearance of which is similar to those induced by $\mathrm{zPrl}-3$ overexpression. Examples of injected embryos depicting the notochord deformation phenotype are photographed at $48 \mathrm{~h}$ post-PRL-3 mRNA (Fig. 6B) or its GFP-PRL-3 plasmid (Fig. 7B) injection. Statistical analysis showed that overexpressing hPRL-3 by either PRL-3 mRNA injection or its plasmids can significantly induce notochord malformation, compared to the control groups (Table II). This phenomenon revealed functional conservation of human Prl-3 and zebrafish PRL-3 in inducing notochord developmental distortion. Furthermore, the abnormal notochords caused by human PRL-3 overexpression were confirmed by ISH as aberrant proliferation of notochord cells with $s h h$ and $n t l$ probes, defining features of chordoma (Fig. 8A and B). Most importantly, PRL-3 was detected in the few clinical chordoma specimens with PRL-3 antibody by immunohistochemistry (IHC) analysis (Fig. 8C), further supporting PRL-3 as a predictor and therapeutic target for chordoma.

\section{Discussion}

Previous reports show that PRL-3 is usually expressed in heart, skeletal muscle and small intestine of mouse tissues $(15,16)$, and similarly expressed in human fetal heart, skeletal muscle and pre-erythrocytes of bone marrow $(9,33)$. However, one recent report showed that PRL-3 is mainly expressed in somites of zebrafish (34). To clarify these confusions, we investigated the dynamic expression pattern of prl-3 in zebrafish and showed that prl-3 is expressed maternally and is ubiquitously expressed in early stages of zebrafish development (Fig. 1B and C). Progressive embryo development from 2 to 4 days post-fertilization results in progressive decline in prl-3 expression but its expression is retained in proliferative areas, including the anterior intestine, esophagus, vessel and notochord (Fig. 1D-F). Hence prl-3 is dynamically expressed during embryonic development.

Given that brachyury ( $n t l)$ is expressed in the zebrafish notochord at the beginning of gastrulation and eventually $n t$ and $s h$ expression are extinguished in notochord when notochord cells becomes vacuolated (26-28), our results revealed that $n t l$ and $s h h$ were persistently expressed in the deformed notochord regions in PRL-3-overexpressed zebrafishes, further highlighting the impact of overt zebrafish and human PRL-3 expression in notochord malformation (Figs. 2B, 4 and 6B). 
A shh probe

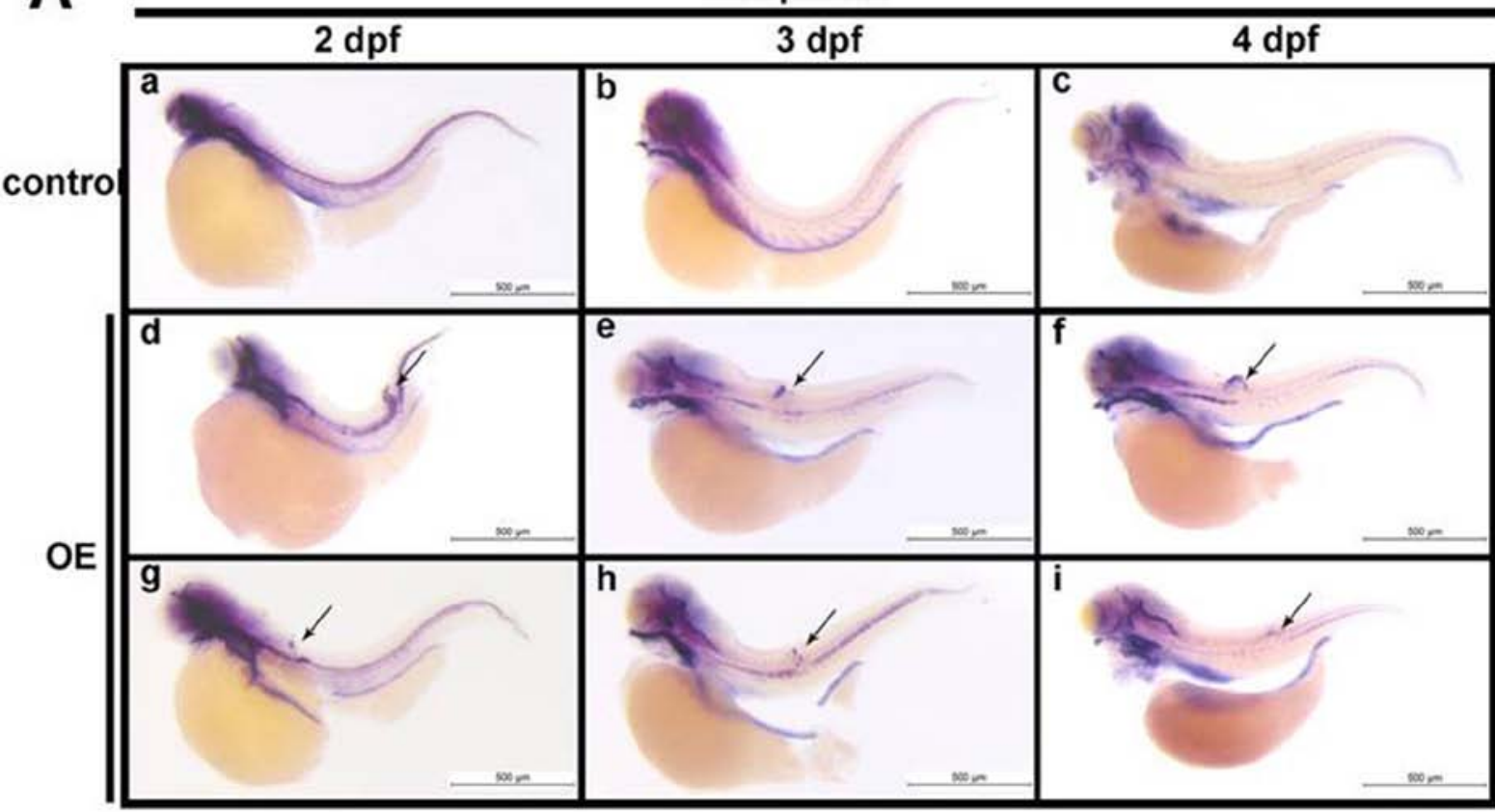

B

\section{ntl probe}

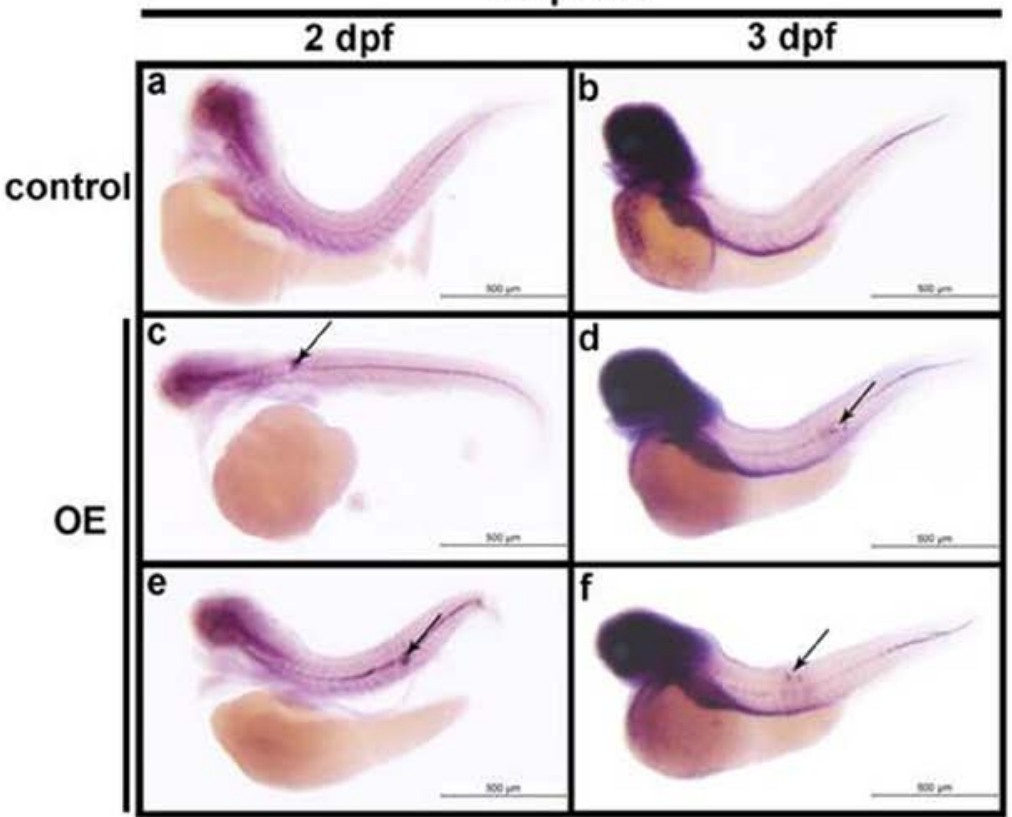

C
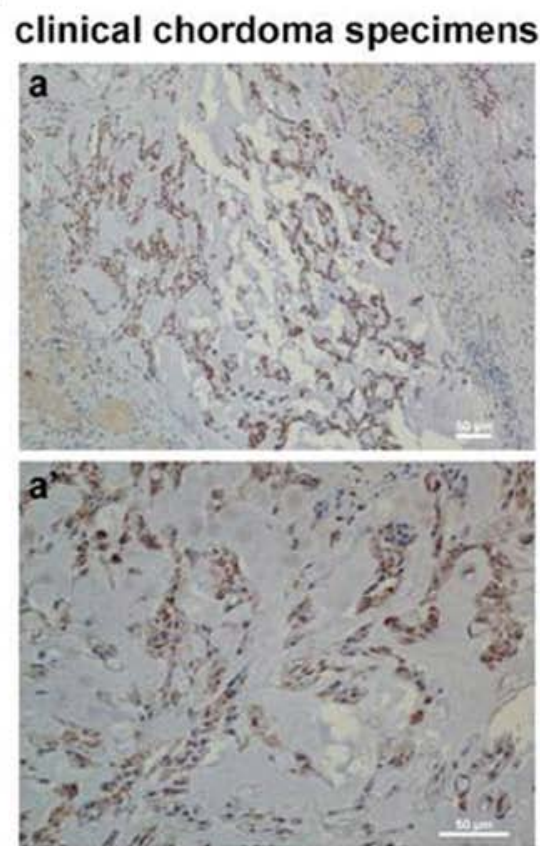

Figure 8. Confirmation of chordoma induced by human PRL-3 overexpression. (A) Whole mount in situ hybridization of shh in control embyos at 2 dpf (a), $3 \mathrm{dpf}$ (b), and $4 \mathrm{dpf}$ (c), compared with that in notochord malformation induced by PRL-3 upregulation (OE) at $2 \mathrm{dpf}(\mathrm{d}$ and $\mathrm{g}$ ), $3 \mathrm{dpf}$ (e and h), and $4 \mathrm{dpf}$ (f and i). The notochord malformation areas with $s h$ positive signals are indicated with arrows. (B) Whole mount in situ hybridization of chordoma-specific $n t l$ in control embyos at $2 \mathrm{dpf}$ (a), $3 \mathrm{dpf}$ (b), compared with that in notochord malformation induced by PRL-3 upregulation (OE) at $2 \mathrm{dpf}$ (c and e), $3 \mathrm{dpf}(\mathrm{d}$ and f). The notochord malformation areas with $n t l$ positive signals are indicated with arrows. Bar length, $500 \mu \mathrm{m}$. (C) Immunohistochemical analysis of PRL-3 upregulation in clinical chordoma specimens and the magnified image is shown in the lower panels.

We further demonstrated for the first time that this notochord deformation is attributed to aberrant proliferation of immature notochord cells (Figs. 5 and 8A and B). Despite the rapid onset of chordoma in zebrafish embryos, developed tumors have similar histological characteristics with that of human chordoma $(20,35)$. Taken together, our discoveries indicate PRL-3 may play an important role in notochord development and aberrant expression of PRL-3 is detrimental to zebrafish embryonic development due to aberrant proliferation of notochord cells. This suggests a key role of PRL-3 in chordoma formation.

Previous studies correlate enhanced PRL-3 expression as a driver of cancer metastasis and a prognostic biomarker for various human cancers $(8,14,36)$. The discovery of high PRL-3 
protein expression in clinical notochordoma samples (Fig. 8C) additionally suggests the possible usage of PRL-3 as a specific biomarker for chordoma diagnosis.

\section{Acknowledgements}

The authors thank Professor Jun Chen, Zhejiang University, for providing the PCS2 plasmid as a gift. We also appreciate Dr Cathleen Teh (IMCB, A*STAR, Singapore) for her helpful editing of this manuscript. This study was supported by National Science Foundation of China (no. 81472730) to W.H. and Guangzhou Science Technology and Innovation Commission (no. 201510010144) to Y.S.

\section{References}

1. Stephens BJ, Han H, Gokhale V and Von Hoff DD: PRL phosphatases as potential molecular targets in cancer. Mol Cancer Ther 4: 1653-1661, 2005.

2. Saha S, Bardelli A, Buckhaults P, Velculescu VE, Rago C, St Croix B, Romans KE, Choti MA, Lengauer C, Kinzler KW, et al: A phosphatase associated with metastasis of colorectal cancer. Science 294: 1343-1346, 2001.

3. Radke I, Götte M, Kersting C, Mattsson B, Kiesel L and Wülfing P: Expression and prognostic impact of the protein tyrosine phosphatases PRL-1, PRL-2, and PRL-3 in breast cancer. Br J Cancer 95: 347-354, 2006.

4. Polato F, Codegoni A, Fruscio R, Perego P, Mangioni C, Saha S, Bardelli A and Broggini M: PRL-3 phosphatase is implicated in ovarian cancer growth. Clin Cancer Res 11: 6835-6839, 2005.

5. Ren T, Jiang B, Xing X, Dong B, Peng L, Meng L, Xu H and Shou C: Prognostic significance of phosphatase of regenerating liver-3 expression in ovarian cancer. Pathol Oncol Res 15: 555-560, 2009.

6. Zhao WB, Li Y, Liu X, Zhang LY and Wang X: Evaluation of PRL-3 expression, and its correlation with angiogenesis and invasion in hepatocellular carcinoma. Int J Mol Med 22: 187-192, 2008.

7. Ooki A, Yamashita K, Kikuchi S, Sakuramoto S, Katada N, Waraya M, Kawamata H, Nishimiya H, Nakamura K and Watanabe M: Therapeutic potential of PRL-3 targeting and clinical significance of PRL-3 genomic amplification in gastric cancer. BMC Cancer 11: 122, 2011.

8. Al-Aidaroos AQ and Zeng Q: PRL-3 phosphatase and cancer metastasis. J Cell Biochem 111: 1087-1098, 2010.

9. Guo K, Li J, Wang H, Osato M, Tang JP, Quah SY, Gan BQ and Zeng Q: PRL-3 initiates tumor angiogenesis by recruiting endothelial cells in vitro and in vivo. Cancer Res 66: 9625-9635, 2006.

10. Wu X, Zeng H, Zhang X, Zhao Y, Sha H, Ge X, Zhang M, Gao X and Xu Q: Phosphatase of regenerating liver-3 promotes motility and metastasis of mouse melanoma cells. Am J Pathol 164: 2039-2054, 2004.

11. Guzińska-Ustymowicz K and Pryczynicz A: PRL-3, an emerging marker of carcinogenesis, is strongly associated with poor prognosis. Anticancer Agents Med Chem 11: 99-108, 2011.

12. Fiordalisi JJ, Keller PJ and Cox AD: PRL tyrosine phosphatases regulate rho family GTPases to promote invasion and motility. Cancer Res 66: 3153-3161, 2006.

13. Liang F, Liang J, Wang WQ, Sun JP, Udho E and Zhang ZY: PRL3 promotes cell invasion and proliferation by down-regulation of Csk leading to Src activation. J Biol Chem 282: 5413-5419, 2007.

14. Wang H, Quah SY, Dong JM, Manser E, Tang JP and Zeng Q: PRL-3 down-regulates PTEN expression and signals through PI3K to promote epithelial-mesenchymal transition. Cancer Res 67: 2922-2926, 2007.

15. Matter WF, Estridge T, Zhang C, Belagaje R, Stancato L, Dixon J, Johnson B, Bloem L, Pickard T, Donaghue M, et al: Role of PRL-3, a human muscle-specific tyrosine phosphatase, in angiotensin-II signaling. Biochem Biophys Res Commun 283 1061-1068, 2001.
16. Zeng Q, Hong W and Tan YH: Mouse PRL-2 and PRL-3, two potentially prenylated protein tyrosine phosphatases homologous to PRL-1. Biochem Biophys Res Commun 244: 421-427, 1998.

17. Zeng Q, Si X, Horstmann H, Xu Y, Hong W and Pallen CJ: Prenylation-dependent association of protein-tyrosine phosphatases PRL-1, -2, and -3 with the plasma membrane and the early endosome. J Biol Chem 275: 21444-21452, 2000.

18. Yang SL, Aw SS, Chang C, Korzh S, Korzh V and Peng J: Depletion of Bhmt elevates sonic hedgehog transcript level and increases $\beta$-cell number in zebrafish. Endocrinology 152: 4706-4717, 2011.

19. Zeng Q, Dong JM, Guo K, Li J, Tan HX, Koh V, Pallen CJ, Manser E and Hong W: PRL-3 and PRL-1 promote cell migration, invasion, and metastasis. Cancer Res 63: 2716-2722, 2003.

20. Burger A, Vasilyev A, Tomar R, Selig MK, Nielsen GP, Peterson RT, Drummond IA and Haber DA: A zebrafish model of chordoma initiated by notochord-driven expression of HRASV12. Dis Model Mech 7: 907-913, 2014.

21. Stemple DL: Structure and function of the notochord: An essential organ for chordate development. Development 132: 2503-2512, 2005.

22. Krauss S, Concordet JP and Ingham PW: A functionally conserved homolog of the Drosophila segment polarity gene $\mathrm{hh}$ is expressed in tissues with polarizing activity in zebrafish embryos. Cell 75: 1431-1444, 1993.

23. Roelink H, Augsburger A, Heemskerk J, Korzh V, Norlin S, Ruiz i Altaba A, Tanabe Y, Placzek M, Edlund T, Jessell TM, et al: Floor plate and motor neuron induction by vhh-1, a vertebrate homolog of hedgehog expressed by the notochord. Cell 76: 761-775, 1994.

24. Yan YL, Hatta K, Riggleman B and Postlethwait JH: Expression of a type II collagen gene in the zebrafish embryonic axis. Dev Dyn 203: 363-376, 1995.

25. Corallo D, Trapani V and Bonaldo P: The notochord: Structure and functions. Cell Mol Life Sci 72: 2989-3008, 2015.

26. Halpern ME, Ho RK, Walker C and Kimmel CB: Induction of muscle pioneers and floor plate is distinguished by the zebrafish no tail mutation. Cell 75: 99-111, 1993.

27. Kispert A and Hermann BG: The Brachyury gene encodes a novel DNA binding protein. EMBO J 12: 4898-4899, 1993.

28. Schulte-Merker S, Ho RK, Herrmann BG and NüssleinVolhard C: The protein product of the zebrafish homologue of the mouse $\mathrm{T}$ gene is expressed in nuclei of the germ ring and the notochord of the early embryo. Development 116: 1021-1032, 1992.

29. Barresi V, Ieni A, Branca G and Tuccari G: Brachyury: A diagnostic marker for the differential diagnosis of chordoma and hemangioblastoma versus neoplastic histological mimickers. Dis Markers 2014: 514753, 2014.

30. Nibu Y, José-Edwards DS and Di Gregorio A: From notochord formation to hereditary chordoma: The many roles of Brachyury. BioMed Res Int 2013: 826435, 2013.

31. Schulte-Merker S, van Eeden FJ, Halpern ME, Kimmel CB and Nüsslein-Volhard C: no tail (ntl) is the zebrafish homologue of the mouse T (Brachyury) gene. Development 120: 1009-1015, 1994.

32. Kispert A and Herrmann BG: Immunohistochemical analysis of the Brachyury protein in wild-type and mutant mouse embryos. Dev Biol 161: 179-193, 1994.

33. Dumaual CM, Sandusky GE, Crowell PL and Randall SK: Cellular localization of PRL-1 and PRL-2 gene expression in normal adult human tissues. J Histochem Cytochem 54: 1401-1412, 2006

34. Lin MD, Lee HT, Wang SC, Li HR, Hsien HL, Cheng KW, Chang YD, Huang ML, Yu JK and Chen YH: Expression of phosphatase of regenerating liver family genes during embryogenesis: An evolutionary developmental analysis among Drosophila, amphioxus, and zebrafish. BMC Dev Biol 13: 18, 2013.

35. Ferrari L, Pistocchi A, Libera L, Boari N, Mortini P, Bellipanni G, Giordano A, Cotelli F and Riva P: FAS/FASL are dysregulated in chordoma and their loss-of-function impairs zebrafish notochord formation. Oncotarget 5: 5712-5724, 2014

36. Peng L, Ning J, Meng L and Shou C: The association of the expression level of protein tyrosine phosphatase PRL-3 protein with liver metastasis and prognosis of patients with colorectal cancer. J Cancer Res Clin Oncol 130: 521-526, 2004. 